\title{
A democracia na penumbra
}

\author{
Gabriel Fernandes Rocha Guimaräes*
}

Costa Pinto, António; Martinho, Francisco Carlos Palomanes (Org.). O passado que náo passa: a sombra das ditaduras na Europa do Sul e na América Latina. Rio de Janeiro: Civilização Brasileira, 2013. 336p.

Recentemente muito se tem falado nos círculos intelectuais e na grande mídia acerca do golpe militar de 1964 e de que forma ele moldou a política brasileira durante o regime implementado, e mesmo depois, já no período da chamada redemocratizaçáa, que tipo de herança política ele deixou, seja de caráter institucional ou ligado à cultura política nacional. Muito se tem especulado acerca deste período. Alguns afirmando que se tratou de um dos maiores, se não o maior, trauma político da história nacional, outros dizendo que foi o solapamento de uma jovem e incipiente democracia brasileira. Há ainda aqueles que falam do golpe como uma resposta a um crescente ganho de força dos grupos de ideologia comunista no Brasil, seja através de guerrilhas rurais, seja através da criação de quadros marxistas dentro das forças armadas, sobretudo no médio e baixo oficialatos.

Embora essas correntes analíticas estejam em debate desde a década de oitenta do século passado, foi nos últimos anos que a discussão se tornou mais acirrada. Então fica a pergunta: por que apenas em governos ou períodos específicos a busca pela "verdade" e pelo passado ganha maiores impulsos? Por que o passado é visto como alvo de uma averiguaçáo mais profunda em certos contextos e em outros não? Por que em certos contextos se defende um maior silêncio em relação a passados ditatoriais sob o argumento de que não é bom para uma democracia nascente abrir velhas "feridas", e em outros se argumenta que as "feridas" devem ser reabertas justamente em benefício da democracia? Por que em alguns casos os "regimes de transição" parecem remediar bastante os traumas políticos gerados por regimes autoritários (como na Grécia) e em outros se dá lugar a um silêncio que só será contestado muitos anos depois (como na Espanha)? É sobre esta problemática que $O$ passado que não passa, livro organizado por Antônio Costa Pinto e Francisco Carlos Palomanes Martinho vai tratar analisando países sul-americanos com ênfase no Brasil e países da Europa do sul, colocando em foco Portugal, Espanha, Itália e Grécia.

Os diversos autores que escrevem no livro organizado por Costa Pinto e Martinho

DOI - http://dx.doi.org/10.1590/2237-101X0173216

* Doutorando em Sociologia pelo Iesp-Uerj, Rio de Janeiro, RJ, Brasil. E-mail: gabrielfrg@bol.com.br. 
tentam mostrar como e por que surgem as "políticas do passado", quais os grupos que as defendem, se elas vêm à tona durante a redemocratização, através dos "regimes de transição", ou anos, ou mesmo décadas depois de fim dos regimes autoritários. Os países da Europa do sul, como Itália, Portugal, Espanha e Grécia trataram de formas bastante diferentes o seu passado, uma vez que o modo como lidaram com as principais lideranças dos regimes autoritários imediatamente à queda destes mesmos regimes foi muito diverso.

O regime fascista italiano teria caído no contexto de uma sangrenta guerra civil entre fascistas e partisans comunistas no norte italiano, além de uma invasão de forças norte-americanas e inglesas que avançou a partir do sul. Os saneamentos ligados a cargos políticos e burocráticos, protagonizados pela esquerda radical, fizeram com que 309 dos 420 senadores fossem afastados de seus cargos, assim como todos aqueles que ocupavam cargos nos níveis mais altos da administração pública. Os saneamentos selvagens que foram administrados pelos partisans junto ao desmantelamento do paraestado fascista foram uma das primeiras medidas tomadas pela esquerda radical enquanto o regime desmoronava. Estimou-se que entre doze e quinze mil supostos agentes do fascismo tenham sido fuzilados através de processos de justiça sumária. O Comitê de Liberação Nacional (CLN), durante a libertação e depois dela limitou-se e comprometeu-se a cumprir as ordens das autoridades aliadas, sendo que a defesa dos saneamentos selvagens e da condenação daqueles que deram suporte aos fascistas, após o término da segunda guerra, ficou a cargo, sobretudo da esquerda radical, o PCI (Partido Comunista Italiano), e na região mais ao norte, seu líder Palmiro Togliatti defendeu a necessidade do "sagrado ódio do povo" se manifestar contra seus antigos opressores. No sul, por outro lado, adotava-se uma posição mais conservadora, preferindo-se "esquecer" o passado fascista tendo em vista a necessidade de pôr fim aos conflitos fratricidas que desde o período da guerra assolavam a sociedade italiana. Os partidos de direita foram revitalizados após a guerra e o movimento Uomo Qualunque, (homem comum) que tanto havia se oposto aos saneamentos, assim como à CLN, conseguiu assegurar a reabilitação de muitos que haviam sido saneados.

O legado do regime fascista italiano persiste até os dias de hoje, de acordo com o artigo, através das disputas entre partidos de direita e de esquerda. Os primeiros defendendo a ideia de que os partidos de direita do pós-guerra impediram que o comunismo, uma força supostamente mais violenta que o fascismo, tomasse o poder na Itália, e os segundos colocando os partisans comunistas como os responsáveis pela derrocada do regime mais tirânico que seu país conheceu. Muitas vezes a esquerda italiana associa a direita de Berlusconi a uma retomada do fascismo na Itália, sendo que a memória do passado está bastante viva no presente político italiano.

Os portugueses, por sua vez, não desmantelaram estruturas paraestatais como os italianos, nem promoveram saneamentos selvagens tão violentos após o fim do regime 
autoritário em 1974 (estes ficaram restritos a algumas áreas do norte português). Os acertos de contas com o passado dirigiram-se, sobretudo, à PIDE, a polícia secreta do regime salazarista, que atuava tanto em Portugal quanto nas colônias africanas. Assim como na Itália, a demanda por justiça em relação a todos que, de alguma forma, colaboraram com o regime foi encabeçada pelos partidos colocados mais à esquerda do PS (Partido Socialista) no espectro político, no caso o PCP (Partido Comunista Português) e a UDP (União Democrática Popular), de inspiração maoista. A UDP, inclusive, defendia execuçôes sumárias, nos moldes dos partigiani italianos definidas por tribunais revolucionários populares, para quem tivesse apoiado o regime. No entanto, assim como o PCP, obtiveram pouco apoio popular.

Os saneamentos feitos no sistema burocrático e administrativo encontraram os mesmos problemas que na Itália, uma vez que provar definitivamente quem apoiava integralmente o regime ou não era muito difícil, e julgar todos os suspeitos gerava o risco de paralisia de toda a estrutura burocrática nacional. Apesar do forte apelo feito pelo PCP e pela UDP, dos saneamentos feitos dentro da PIDE e do caráter revolucionário da fratura política, o regime de transição português se caracterizou por uma posição relativamente moderada (pelo menos se compararmos com o caso italiano), no sentido de que as demandas comunistas-maoístas foram amenizadas por uma espécie de apatia de boa parte da sociedade portuguesa em relação a tais propostas. ${ }^{1}$ A maioria da socie-

\footnotetext{
${ }^{1}$ Não se quer dizer que na Itália não houve de for-
}

dade lusitana se contentou com a prisão dos membros da PIDE como forma de acertar as contas com o antigo regime de Salazar e Marcello Caetano. A memória popular ligada ao regime do Estado Novo ficou muito vinculada à imagem de Marcello Caetano que, segundo os autores, teve a sua principal faceta, a de um grande intelectual, apagada da memória popular em função de momentos esporádicos de sua carreira, como a repressão à Capela do Rato ou as restriçóes às listas eleitorais de 1969 e 1973 . Dois anos após a queda do regime, o que se viu foi um quase desaparecimento das políticas do passado. A vitória do PS em 1976 deu continuidade a este processo de esquecimento e de reconciliação frente a processos de caráter mais punitivo.

Já o caso espanhol aparece como um dos mais curiosos, uma vez que, mesmo com a violência e grande duração (36 anos) do regime de Franco, as políticas do passado e a busca pela verdade só vieram à tona já adentrado o novo século, tendo havido uma espécie de esquecimento que durou décadas até ser ativado pelo governo de Zapatero. Ao contrário do caso italiano, em que o regime de Mussolini caiu frente a uma violenta guerra civil, ou do caso português, que viu o regime ruir frente a um movimento revolucionário que se desenvolveu dentro das Forças Armadas em um contexto de guerra colonial, o regime franquista espanhol nasceu, se desenvolveu e morreu com Franco. O ditador faleceu de

ma alguma um desinteresse popular pela extrema esquerda. Queremos dizer apenas que a esquerda radical italiana conseguiu capitalizar o processo de saneamento do regime fascista por mais tempo e de forma mais contundente. 
velho em sua cama em 1975, em uma conjuntura de pouco conflito político-militar, com a monarquia logo tomando as rédeas do processo de democratização.

De certa forma, as elites que conduziram a redemocratização insistiram em um argumento utilizado pelo próprio Franco de que os espanhóis seriam inaptos para viver em democracia sem recorrer à violência. Embora essas elites conduzissem o sistema rumo a uma democracia, este argumento foi utilizado no sentido de estabelecer rapidamente um discurso de reconciliação e evitar novos confrontos que pudessem vir à tona junto com a busca pelas raízes do governo franquistas. Isto se traduziu numa procura obsessiva pelo consenso, e um princípio indispensável durante o governo de transição. Desta maneira, o argumento de Franco foi utilizado de forma ex negativo como forma de superação do regime do próprio Franco.

A transição para a democracia foi, em alguma medida, baseada num desejo quase explícito de esquecer, ou mesmo silenciar as dimensóes do passado. A Lei de Anistia de 1977 para crimes políticos, votada no Parlamento por todos os partidos, menos a ala de direita dos ex-franquistas, satisfez, sobretudo bascos e catalães, que haviam sofrido repressão direta do regime. Entretanto, essa lei protegia de açóes judiciais também os perpetradores da ditadura. O referendo para Lei para a Reforma Política de 1976, que estabelecia a lei como princípio político e a soberania do povo através do sufrágio geral teve amplo apoio popular (77\% votou pelo sim) e a maioria dos partidos políticos espanhóis optou pela moderação.
Os primeiros sinais da necessidade de pensar o passado vieram com as pensóes destinadas a viúvas de militares republicanos mortos na guerra civil, e a reabertura de valas comuns em certos municípios, onde estariam enterrados membros da oposição assassinados pelo regime. A reabertura das valas foi uma iniciativa popular situada, sobretudo, em pequenos municípios, canalizadas por parlamentares recém-eleitos das câmaras municipais, mas as iniciativas de "desenterro" do próprio passado ficaram reduzidas a isso. Mesmo com o PSOE vencendo as eleições espanholas de 1982 e 1986, pouco se propôs para uma maior averiguação do passado ditatorial. Apenas com o PP (Partido Popular), um partido de direita chegando ao poder em 1996, começou-se realmente a tentar desvelar o passado franquista. A política do passado se fez incisivamente relevante no presente, assumindo um ponto central no discurso da esquerda a partir de 2000. O PSOE passou a associar a direita espanhola de forma geral com a ditadura franquista, de maneira a enquadrá-la como a revitalização de um passado sombrio, cabendo à esquerda a tarefa de barrar esta suposta ameaça. Desta forma, a averiguação do passado ditatorial está intrinsecamente ligada a um discurso partidário de plataformas eleitorais de esquerda como PSOE, IU (Izquierda Unida), ERC (Esquerra Republicana de Catalunya) e vivo no presente político espanhol, como no caso da ARMH (Associação para a Recuperação da Memória Histórica) fundada no ano 2000. De qualquer forma, os próprios autores concordam que a necessidade de recuperar 
a "verdade" acerca do passado autoritário na Espanha ter ocorrido apenas nestas datas específicas permanece uma questão a ser estudada mais minuciosamente.

No caso grego, curiosamente parece ter ocorrido justamente o contrário. $\mathrm{O}$ "governo dos coronéis" caiu em 1974, sendo que suas mais proeminentes lideranças foram presas e condenadas quase que imediatamente ao fim do regime. Isto parece ter, em alguma medida, saciado a necessidade de acerto de contas com o passado, visto que o tema da ditadura militar parece ter sido "apagada" da memória coletiva dos gregos. À queda do regime sucedeu o retorno do conservador Konstantinos Karamanlis ao poder, o mesmo que havia sido deposto em 1967 pelos militares. Quando da queda dos militares o partido mais à esquerda, o Partido Comunista da Grécia (EKK), curiosamente não foi quem colocou demandas mais radicais em relação ao que fazer com os administradores da ditadura. Quem assumiu esta posição foi o Partido Socialista Grego (PASOK). Isto se deve, segundo o autor, ao fato de muitos membros do EKK terem vivenciado a semidemocracia de antes da ditadura, onde partidos socialistas e comunistas eram proibidos de competir em eleiçôes. Para os membros do EKK, o direito às eleiçôes após o fim da ditadura já era um grande ganho e tinham receios do que poderia ocorrer caso colocassem demandas demasiadamente radicais, tendo em vista as perseguiçóes que sofreram durante os governos conservadores de antes do regime dos coronéis. Os mais jovens membros do PASOK, náo tendo tão fresca a memória acerca dos regimes conservadores, não hesitavam em exigir penas duríssimas para os responsáveis pela ditadura. Por causa desta questão geracional, os gregos inverteram a regra portuguesa, onde os comunistas haviam assumido um maior radicalismo e os socialistas uma maior moderação. Com a condenaçáo à prisão perpétua de três dos principais membros dos círculos governantes, a necessidade de desenterrar o passado ficou no próprio passado, no caso grego.

Voltando nosso olhar para a América do Sul, o Brasil foi o maior alvo da atenção dos autores. De acordo com Palomanes Martinho, os silêncios acerca da ditadura no Brasil foram vários, incluídos aqueles em torno das iniciativas políticas institucionais e extrainstitucionais da esquerda antes do golpe e aquele em torno dos torturadores, que parece ocupar um lugar central nos atuais debates acerca do tema. A averiguação dos crimes cometidos pelo regime militar, no caso brasileiro, também teve, no início, iniciativas bastante tímidas. Elas se limitaram às buscas do frade franciscano Paulo Evaristo Arns e do pastor presbiteriano Jaime Wright, ainda durante o regime (entre 1979 e 1985) por meio de documentos confidenciais acerca do julgamento de 707 "subversivos" julgados pelo Superior Tribunal Militar (STM). No governo Collor, muito pouco se fez para aprofundar um anseio que já se desenvolvia em alguns setores da sociedade civil desde a década de 1980: acesso aos arquivos em busca da verdade acerca dos mortos e desaparecidos.

Foi no governo FHC que começaram medidas mais significativas em relação ao passado ditatorial. Em 1995 a Comissão 
de Familiares dos Mortos e Desaparecidos por Razôes Políticas (CFMDRP) publicou o "Dossiê das mortes e desaparecimentos políticos a partir de 1964" e o governo respondeu apresentando um projeto de lei para reconhecer a morte dos 136 presos políticos e compensar as famílias dos mortos e dos torturados. $\mathrm{O}$ governo também assinalou o décimo sexto aniversário da Lei de Anistia, que liberou presos políticos e torturadores de qualquer forma de processo por parte do Estado. Ainda em 1995, a Lei das Vítimas de Assassinato e Desparecimento Político tornou-se o eixo da "justiça de transiçáo" do governo FHC. Ela reconhecia a responsabilidade do Estado pela morte de 136 militantes políticos e estabelecia a criação da Comissão Especial sobre Mortos e Desaparecidos Políticos com o objetivo de analisar esses e outros casos pendentes, além de comprometer o governo com o pagamento de indenizações às famílias das vítimas.

O governo Lula deu continuidade a essas propostas, aprofundando-as através de uma nova Comissão de Anistia e do estabelecimento de uma Comissão Nacional da Verdade promovendo um conjunto de "políticas da memória”. O governo Lula representou o primeiro esforço oficial para contar a verdade desde os esforços de Arns nos anos 1980. Entretanto, deparou-se com as mesmas dificuldades encontradas durante o governo FHC, em particular com a resistência dos militares em abrir os arquivos e com a forte resistência contra a violaçáo dos limites impostos pela Lei de Anistia. No governo Dilma Rousseff este processo se aprofundou realmente. A política do passado ganhou to- nalidades mais gritantes. Ao passar a Lei da Comissão da Verdade, a presidente Dilma também sancionou a Lei de Acesso à Informação, que permitiria aos cidadãos entrar em contato com os documentos governamentais. Esta lei entrou em vigor em 2012 e garantiu acesso a documentos públicos de órgãos federais. Porém, a existência dos tribunais separados para a polícia militar continua gerando certo clima de impunidade e de continuidade de certos traços do regime ditatorial, permanecendo como um dos principais temas de conexão entre as políticas do passado e do presente.

Encontrar um eixo comum que caracterize todos os casos estudados se mostra bastante difícil, no que se refere ao momentum em que essas reivindicaçóes são de fato postas em prática. A busca pela verdade e pelo acerto de contas pode vir ainda durante o regime, mas ganhar contornos mais incisivos apenas anos depois, como no Brasil. Pode também vir à tona apenas décadas depois como no caso espanhol. Segundo os autores, o passado pode sobreviver e influenciar na luta partidária do presente como na Itália, ou permanecer no passado como na Grécia e, em certa medida, Portugal.

Os gregos, inclusive, foram o caso mais claro de esquecimento do passado autoritário, talvez porque os principais responsáveis tenham imediatamente recebido penas duríssimas, satisfazendo assim o desejo de retaliação de certos setores sociais. $\mathrm{O}$ que podemos ver em todos os casos analisados é que são basicamente os setores de esquerda que reivindicam a luta pela memória. Tanto nos regimes de transição, onde a esquerda 
radical defende muitas vezes julgamentos populares para os suspeitos, quanto já no período democrático, onde a esquerda clama para si o papel de antagonista daqueles que supostamente ainda perpetuam certos traços das ditadura, ela em todos os casos analisados assume o papel de grande adversário do espírito autoritário que dominou seus países, mesmo em situaçóes onde grande parte da população não esteja tâo interessada na questấo, como em Portugal. Isto se deve, muito provavelmente, ao fato de todos os regimes estudados no livro terem sido ditaduras de direita. Mas fica a pergunta: a esquerda, e sobretudo, a esquerda radical, entra em cena nesses momentos para lutar por um regime poliárquico no sentido de Robert Dahl, ou para alavancar um processo revolucionário extra, ou intraparlamentar? Seria interessante um aprofundamento deste estudo comparando os casos analisados com os países do leste europeu, seus regimes de transiçáo, quais atores afrontaram os regimes autoritários e como o fizeram, e de que maneira o passado influencia na política do presente. 